DOI: https://doi.org/10.24867/07AM10Sarovic

\title{
PRIMENA AUTOMATIZACIJE PODSTANICA U SISTEMIMA DALJINSKOG GREJANJA
}

\section{APPLICATION OF SUBSTATION AUTOMATION IN DISTRICT HEATING SYSTEMS}

\author{
Dušan Šarović, Fakultet tehničkih nauka, Novi Sad
}

\section{Oblast- TERMOENERGETIKA}

Kratak sadržaj - Ovaj rad prikazuje kompatibilan izbor opreme za automatizaciju i prilikom ugovaranja radova po sistemu „ključ u ruke“. Ugovaranje, projektovanje, nezaobilazno korišćenje zakonskih okvira, adekvatan izbor $i$ instalaciju automatizovane opreme, za toplotno područje grada Novog Sada, odnosno toplotnih podstanica kod svake grupe potrošača, optimalan izbor $i$ način rada kompletne opreme.

Ključne reči - Daljinsko grejanje, automatizacija podstanica

Abstract - This paper shows a justified selection of automation equipment when contracting works are on a turnkey basis. Contracting, designing, use of legal frameworks, adequate selection, and installation of automated equipment for the district heating area of the city of Novi Sad. Paper provided a complete solution for thermal substations, optimal choice and operation of its necessary equipment.

Keywords - District heating, substation automation

\section{UVOD}

Današnjica nalaže racionalizaciju korišćenja, odnosno smanjenje rasipanja energije u celom energetskom lancu: od eksploatacije primarne energije iz prirode, preko transporta, energetskih transformacija i prenosa transformisane energije završno sa korišćenjem finalne energije.

Kako su rezerve fosilnih goriva ograničene, treba ih razumno i racionalno trošiti. Vodeći se tim, potrebe za energijom treba zadovoljiti primenom novih i savremenih energetskih tehnologija koje će najmanje remetiti postojeću ekološku ravnotežu, a sa druge strane uručiti kvalitetan i stabilan vid energije.

Kako je neminovno korišćenje tradicionalnih energenata, intenzivno se radi na usavršavanju tehnologija za eksploataciju i dalju manipulaciju istih, što se jednako odnosi na sve vrste energenata, izmedju ostalih i prirodni gas.

$\mathrm{Na}$ sadašnjem stepenu razvoja tehnologija za energetsku transformaciju, zadovoljavanje potreba za toplotnom energijom uz korišćenje prirodnog gasa, kao najčistijeg fosilnog goriva i kao primarne energije u sistemima daljinskog grejanja, na najbolji način zadovoljava racionalizaciju potrošnje u odnosu na ostala fosilna goriva.

\section{NAPOMENA:}

Ovaj rad proistekao je iz master rada čiji mentor je bio doc. dr Aleksandar Anđelković.
Kako postoji tendencija za sve većim korišćenjem toplotne energije u centralizovanim sistemima, potrebno ju je na najbolji način transformisati i plasirati, uz najmanji procenat gubitaka.

Dobra praksa „Novosadske toplane“ na najbolji način pokazuje korišćenje i manipulaciju energijom. Od baznog izvora, prirodnog gasa, transformacije energije kroz kogenerativne sisteme, dalji plasman i distribuciju toplotne energije do krajnjih korisnika kroz regulaciju u toplotnim podstanicama.

Automatizacijom primarnih i sekundarnih toplotnih podstanica kod krajnjih korisnika omogućuje se fina regulacija, plasman toplotne energije ka potrošačima i smanjenje konkretne proizvodnje u izvorima u periodima kada spoljna temperatura raste.

\section{USLOVI ZA UGOVARANJE, PROJEKTOVANJE I IZVOĐENJE}

Specifikacija postojećeg stanja sa spiskom primarnih podstanica sa pripadajućim sekundarnim toplotnim podstanicama za koje je potrebno dimenzionisati, izraditi projektno rešenje - Projekat za izvođenje -PZI, izabrati i ponuditi mašinsku opremu, pri čemu je predviđena:

Zamena i ugradnja svih hvatača nečistoća na primarnom delu toplotne podstanice ispred regulatora pritiska i na sekundarnom delu toplotne podstanice ispred kombi ventila.

Zamena svih regulatora pritiska koji nisu proizvođača "Danfoss" ili "Samson" - regulatori pritiska moraju biti sa sigurnosnom funcijom (dvostrukom membranom);

Zamena svih sigurnosnih ventila koji nisu proizvođača "Danfoss", "Samson" ili "Berluto";

Ugradnja kombi regulatora protoka sa elektromotornim pogonom na svim regulacionim krugovima za grejanje,

Zamena svih prolaznih ventila na toploj potrošnj vodi TPV koji nisu proizvođača "Danfoss" ili "Samson", odnosno koji su sa elektromotornim pogonom - EMP koji imaju napon napajanja $24 \mathrm{~V}$, strana 8 od 208

Ugradnja senzora temperature i sigurnosnih termostata sa odgovarajućim čaurama od nerđajućeg čelika,

Ugradnja senzora pritiska u 40 referentnih toplotnih podstanica koje će Naručilac definisati pre početka izvođenja radova.

Ugradnja prestrujnog ventila na povratu između hvatača nečistoće i kombi ventila. 


\section{ODABIR ADEKVATNE KLJUČNE OPREME:}

Dimenzionisanje i izbor elemenata podstanice pomoću kojih se reguliše radni pritisak, protok primarne vode i obezbeđuje sigurnost od prekoračenja radnog pritiska vrši se na osnovu izračunatih protočnih karakteristika ovih elemanata.

Regulator pritiska je uređaj pomoću koga se reguliše pritisak u sekundarnoj podstanici i kućnoj instalaciji.

Kombi regulator sa elektromotornim pogonom za regulaciju protoka na sekundarnoj podstanici za grejanje.

Prolazni ventil sa elektromotornim pogonom je uređaj za regulaciju primarnoj podstanici za TPV.

U jednoj kućnoj podstanici regulatori pritiska i kombi ventili sa elektromotornim pogonom trebaju biti od istog proizvođača. Za regulaciju pritisaka:

- 2,0 - 5,0 bar

- $\Delta$ pmin 1 bar

- Pritisci otvaranja 4,0 do 6,0 bar

- Izračunati protok za $\Delta \mathrm{p}=0,2$ bar

- Nazivni pritisak NP16 bar

- Nazivni otvor min. DN15, max. DN 25

- Pogon sa oprugom Elektromotorni, 230 VAC, IP54, trotačkovni, sa krajnjim prekidačima sa oprugom Elektromotorni, 230 VAC, IP54, trotačkovni, sa krajnjim prekidačima Deklarisanje proizvoda (natpisna pločica na telu ventila $\mathrm{i}$ atest).

Ultra zvučno merilo isporučene toplotne energije bazira se na merenju protoka $\mathrm{i}$ razlike temperatura nosioca toplote sekundarne podstanice.

Merilo toplote sastoji se od sledećih elemenata:

1) ultrazvučnog merila protoka,

2) t emperaturnih senzor na potis vodu,

3) računske jedinice.

4) imaju odgovarajuće rešenje o odobrenju tipa merila,

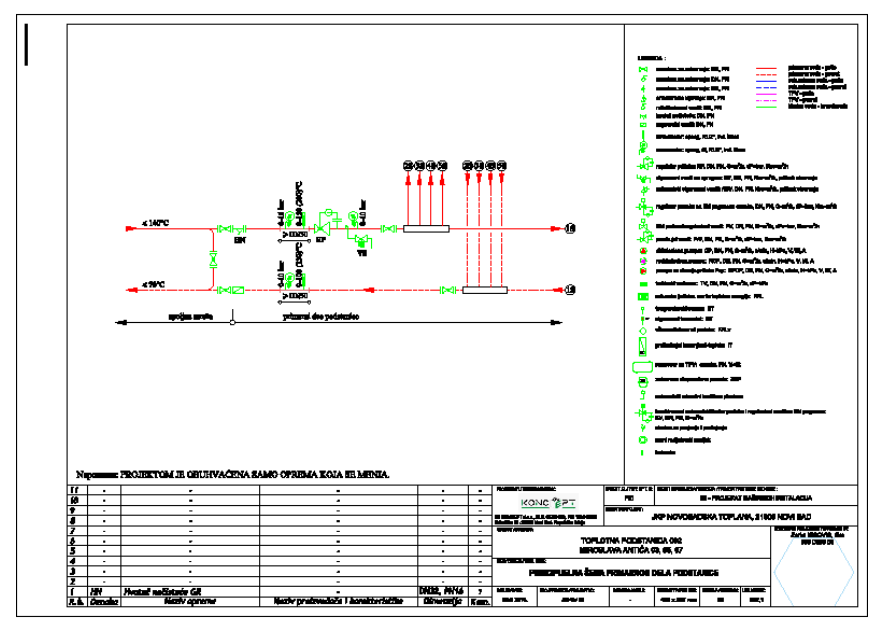

Slika 1. Tehnološka šema primarnog dela automatizovane
toplotne podstanice
Slika 1. Tehnološka šema primarnog dela automatizovane
toplotne podstanice

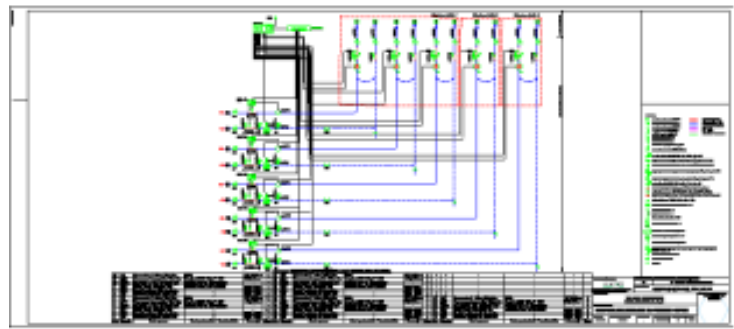

Slika 2. Tehnološka šema primarnog dela automatizovane toplotne podstanice

\subsection{Uređaji za regulaciju pritiska}

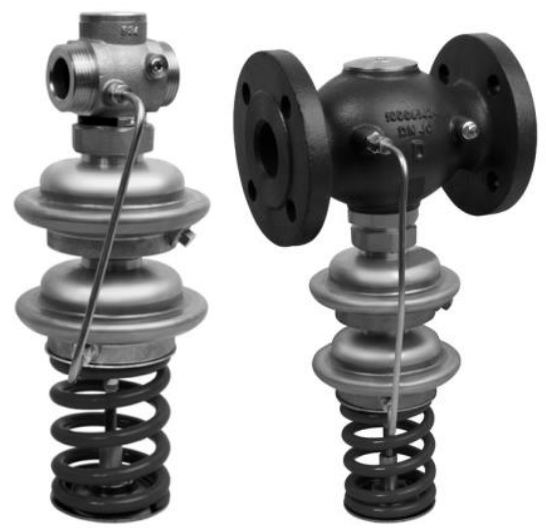

Slika 3. Uređaj za regulaciju pritiska

- Osnovne karakteristike:

- Dimenzije: DN 15-50,

- Maksimalni protok pri padu pritiska od 1 bar do koje ne dolazi do kavitacije unutar uređaja: kVS 4,0$25 \mathrm{~m}^{3} / \mathrm{h}$

- Nazivni pritisak: PN 25,

- Opsezi radnih pritisaka: 1-5/2-8/3-12 bar, Radna temperatura: do $150{ }^{\circ} \mathrm{C}$

\subsection{Uređaji za regulaciju pritiska}

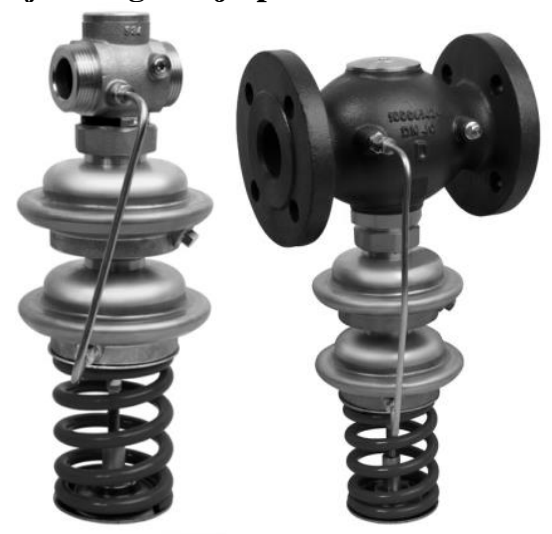

Slika 4. Izgled uređaja za održavanje pritiska 


\subsection{Uređaji za regulaciju protoka}
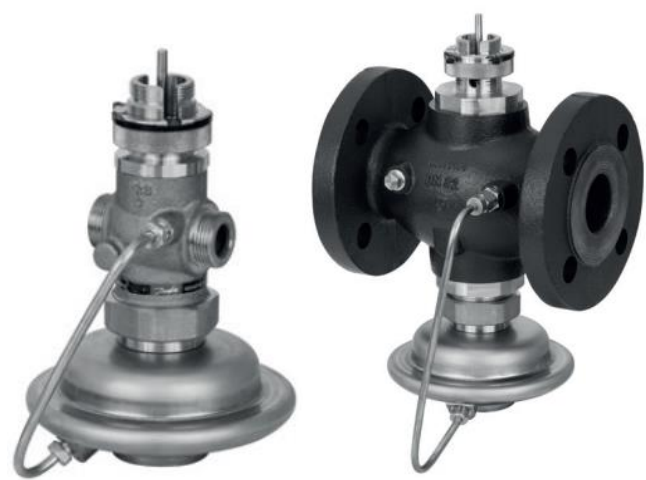

Slika 5. Uređaj za regulaciju protoka

\subsection{Uređaji za ultrazvučno merenje potrošnje toplotne energije}

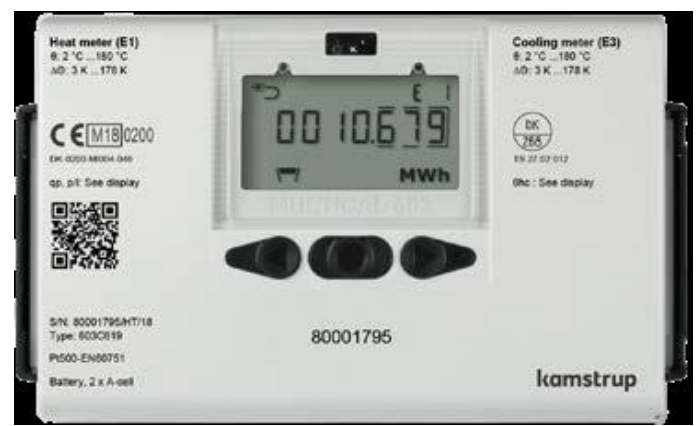

Slika 6. Uređaji za ultrazvučno merenje potrošnje toplotne energije

Ultrazvučno merilo isporučene toplotne energije bazira se na merenju protoka i razlike temperatura nosioca toplote sekundarne podstanice. Merilo toplote sastoji se od sledećih elemenata:

1) ultrazvučnog merila protoka,

2) temperaturnih senzor na potis vodu,

3) računske jedinice.

4) imaju odgovarajuće rešenje o odobrenju tipa merila,

\subsection{Uređaji za merenje, podešavanje i kontrolu} radnih parametara

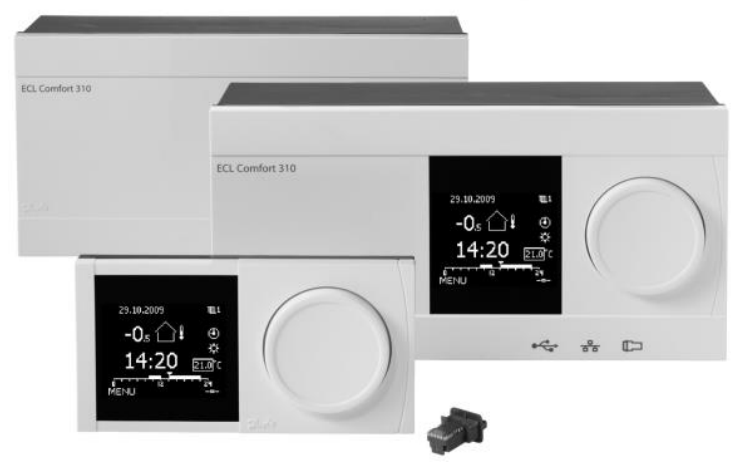

Slika 7. Uređaji za merenje, podešavanje i kontrolu radnih parametara

ECL Comfort 310 je elektronski kontroler za toplotne podstanice u sistemima daljinskog grejanja. Radi na principu regulacije dovodne temperature sekundara zavisno od promene spoljnih uslova. Pripada porodici regulatora ECL Comfort, a koristi se i u sistemima centralnog grejanja i rashladnim sistemima. Ušteda energije može se postići pravilnom regulacijom dovodne temperature u sistemima grejanja i rashladnim sistemima. Moguće je regulisati do 4 kruga.

Funkcija kompenzacije prema spoljnim uslovima u ECL Comfort regulatorima meri spoljnu temperaturu i u skladu sa tim reguliše dovodnu temperaturu za sistem grejanja. Sistem grejanja sa kompenzacijom prema spoljnim uslovima povećava nivo udobnosti i uštedu energije.

ECL Comfort 310 regulator konfiguriše se pomoću izabrane aplikacije putem ECL aplikacionog ključa.

ECL Portal zasnovan na web-u komunicira sa ECL Comfort 310 regulatorom da bi se dobila efikasna i jednostavna SCADA (eng. Supervisory Control And Data Acquisition) alatka koja je spremna za korišćenje i predviđena za sve korisnike, servisno osoblje i pri puštanju u rad. Moguće je povećati nivo servisiranja i/ili smanjiti troškove servisiranja. Instalacijama za grejanje i/ili hlađenje može se pristupiti sa gotovo bilo kog mesta u bilo koje vreme preko laptop računara ili pametnih telefona što povećava nivo servisiranja i smanjuje vreme odziva na alarme.

Softver ECL alatke za ECL Comfort 310 nudi mogućnosti alternativne daljinske kontrole u vezi sa ECL Portalom i softverom OPC servera.

ECL Comfort 310 dizajniran je za postizanje komfornih temperatura, optimalnu potrošnju energije, laku instalaciju putem ECL aplikacionog ključa (Plug-and-Play) i jednostavno korišćenje.

Poboljšanu uštedu energije olakšava kompenzacija prema spoljnim uslovima, podešavanje temperature u skladu sa potrebama, optimizacija, kao i ograničenje temperature povrata, protoka i snage.

ECL Comfort 310 lako se koristi putem točkića (multifunkcionalnog tastera) ili jedinice za daljinsko upravljanje (RCU). Točkić i osvetljeni ekran vode korisnika kroz tekstualne menije na izabranom jeziku.

ECL Comfort 310 regulator, između ostalog, ima električne izlaze za regulaciju motornog ventila, relejni izlaz za regulaciju cirkulacione pumpe/ changeover ventila, kao i izlaz alarma.

Moguće je priključiti 6 temperaturnih senzora Pt 1000 . Pored toga, 4 ulaza se konfigurišu zavisno od aplikacije. Konfiguracija može biti ulaz temperaturnog senzora Pt 1000 , analogni ulaz $(0-10 \mathrm{~V})$ ili digitalni ulaz.

U zavisnosti od aplikacije, interni dodatni modul ECA 32 (ubacuje se u podnožje regulatora) može davati dodatne ulazne i izlazne signale.

Podnožje je dizajnirano za montiranje na zid ili DIN šinu. Dostupna je varijanta regulatora ECL Comfort 310B (bez

\section{ZAKLJUČAK}

Cilj ovog rada je bio prikaz racionalnog korišćenja toplotne energije pri distribuciji i generalnom distributivnom sistemu Novosadske toplane. Tendencija sprovođenja definisane strategije i planom automatizacije i povezivanja na sistem daljinskog nadzora i upravljanja 
svih primarnih podstanica, što je kao distributer toplotne energije u obavezi prema članu 51 Zakona o efikasnom korišćenju energije („Službeni glasnik RS” 55/2013).

Opštepoznati podatak na području Srbije, jeste da se tokom grejne sezone „baci” velika količina toplotne energije.

Kako dnevni gradijent temperature tokom grejne sezone varira, potreban je sistem koji će odgovoriti zahtevima potrošača a naročito povećati efikasnost transformacije, plasmana i isporuke energije. Upravo se ovakav način kvalitetno isporučene energije postiže automatizacijom prvobitno izvora, zatim distibutivnog sistema i konačno predajne stanice odnosno podstanice. Konkretan primer ugovaranja, projektovanja - odabira adekvatnih elemenata, izvođenja i pratećih pravilnika i zakona opisanih u ovom radu.

Za poboljšanje sistema, adekvatan i dovoljan plasman toplotne energije, Novosadska Toplana je raspisala niz tendera za Automatizaciju toplotnih podstanica. Do današnjeg dana automatizovano je gotovo $70 \%$ toplotnih podstanica, gde je ostvarena velika ušteda.

\section{LITERATURA}

[1] Proračun toplotne podstanice, Novi Sad, 2015.

[2] Gojnić M, Tehnoekonomska analiza toplotne podstanice, Novi Sad, 2015.

[3] Tehnički opis toplana, Beograd, 2016.

[4] Projektni zadatak Automatizacija podstanica 2018.

[5] Petrović J, SAVREMENE ENERGETSKE

TEHNOLOGIJE-, izvodi iz doktorske teze, Novi Sad, 2007

[6] http://www.ingkomora.org.rs/ 27.09.2019.

[7] http://www.aers.rs/ 12.09.2019.

\section{Kratka biografija:}

Dušan Šarović rođen je u Novom Sadu 1993. god. Osnovne studije na Fakultetu tehničkih nauka iz oblasti Energetika i procesna tehnika završio je 2016. god. Trenutno student master studija na smeru Energetika i procesna tehnika-termoenergetika. 